\title{
ALTERAÇÕES CRONOLÓGICAS DO PERFIL DOS PACIENTES E DA MODALIDADE DE TRATAMENTO CIRÚRGICO DO MEGAESÔFAGO CHAGÁSICO ${ }^{1}$
}

\author{
Reginaldo Ceneviva ${ }^{2}$ \\ Ruy Ferreira-Santos ${ }^{3}$ \\ José Sebastião dos Santos ${ }^{4}$ \\ Ênio David Mente 5 \\ Ajith Kumar Sankarankutty ${ }^{6}$
}

\section{RESUMO}

Objetivo - Analisar eventuais mudanças no perfil de pacientes com megaesôfago chagásico e na escolha da modalidade de tratamento cirúrgico, mediante estudo comparativo de dois grupos de pacientes em períodos diferentes. Métodos - Foram analisadas duas séries consecutivas de pacientes com megaesôfago chagásico tratados cirurgicamente em dois períodos de tempo: de 1955 a $1962 \quad(\mathrm{n}=147)$ e de 1988 a 1998 $(\mathrm{n}=100)$. A idade, a duração da disfagia e o estádio evolutivo da doença foram correlacionados com o tipo de cirurgia realizada. O grau do megaesôfago foi definido mediante exame radiológico padronizado. Resultados - Houve redução no número de pacientes, aumento da idade média e diminuição da duração da disfagia no segundo período. As cirurgias de ressecção esofágica predominaram no primeiro e a cardiomiotomia no segundo período. Conclusões - O perfil dos pacientes com megaesôfago chagásico atendidos no HCFMRP-USP mudou, caracterizando-se pelo estádio mais precoce da doença. A assistência médica mais precoce resulta em modalidade terapêutica cirúrgica menos agressiva, com perspectiva de melhores resultados. Disponível em URL: http://www.scielo.br/acb

Descritores - Megaesôfago chagásico; Perfil do paciente; Tratamento Cirúrgico.

\section{ABSTRACT}

Objective - To analize the changes in the profile of the patients with chagasic megaesophagus and treatment modalities by comparing two groups of patients in different time periods. Methods - Two series of consecutive patients with chagasic megaesophagus treated surgically were analized in two different time periods, between 1955 and $1962(\mathrm{n}=147)$ and between 1988 and1998 $(n=100)$. The age, duration of disphagia and the stage of the disease were correlated to the type of surgical procedure. The degree of megaesophagus was defined radiologically. Results - There was a reduction in the number of patients, an increase in the median age and a reduction in the duration of disphagia in the second time period. During the first period, ressectional procedures were more common, while cardiomiotomy predominated in the second. Conclusions - The profile of the patients with chagasic megaesophagus, treated at the HCFMRP-USP, has changed along the years, the main change being earlier stages of the disease. Earlier medical assistance results in less aggressive surgical procedures with the perspective of better outcomes.

Key Words - Chagasic megaesophagus; Patient profile; Surgical treatment.

\section{INTRODUÇÃO}

Pela sua gravidade potencial e alta prevalência a doença de Chagas constitui um importante problema médico-social no Brasil; estima-se que cerca de 10 milhões de pessoas estejam afetadas pela doença no país ${ }^{1}$.

\footnotetext{
1 Trabalho realizado no Departamento de Cirurgia e Anatomia da Faculdade de Medicina de Ribeirão Preto da Universidade de São Paulo - FMRP-USP.

2 Professor Titular

3 Professor Titular Emérito

4 Professor Assistente Doutor

5 Médico Assistente do HCFMRP-USP, Doutor pela FMRP-USP

6 Médico Assistente do HCFMRP=USP, Mestre pela FMRP-USP
} 
A distribuição regional é heterogênea, desde regiões em que a doença é endêmica a regiões onde a transmissão vetorial não mais existe.

O Estado de São Paulo não tem mais focos do vetor, mas suas instituições de saúde continuam como centros de referência.

É lícito supor que as alterações epidemiológicas e sanitárias tenham influência no estágio evolutivo com que o paciente procura tratamento e na seleção do tipo de tratamento a ser oferecido.

\section{OBJETIVO}

Analisar eventuais mudanças no perfil de pacientes com megaesôfago chagásico e na escolha da modalidade de tratamento cirúrgico, mediante estudo comparativo de dois grupos de pacientes em períodos de tempo diferentes.

\section{MÉTODOS}

Foram analisadas duas séries consecutivas de pacientes com megaesôfago chagásico atendidos e tratados no Hospital das Clínicas de Ribeirão Preto em dois períodos: de 1955 a $1962(\mathrm{n}=147)^{2}$ e de 1988 a $1998(\mathrm{n}=100)$. A idade, a duração da disfagia e o estádio evolutivo da doença foram correlacionados com o tipo de cirurgia realizada.

O estádio evolutivo da doença foi avaliado mediante classificação do megaesôfago baseada em estudo radiológico; as radiografias eram tomadas em incidência ântero-posterior, mediante técnica padronizada, considerando-se quatro graus de megaesôfago de acordo com seu diâmetro transverso: grau I - até 4 $\mathrm{cm}$; grau II - de 4 a $7 \mathrm{~cm}$; grau III - de 7 a $10 \mathrm{~cm}$; grau IV - acima de $10 \mathrm{~cm}^{3}$. O diagnóstico etiológico da esofagopatia chagásica foi dado pela positividade das reações de fixação de complemento ou de imunofluorescência.

\section{RESULTADOS}

O número total e a média por ano de pacientes e a duração da disfagia podem ser observados na Tabela 1. Houve uma diminuição do número de pacientes por ano, aumento da média de idade e diminuição da duração da disfagia no segundo período.

Tabela 1 - Número de pacientes, média e duração da disfagia de pacientes com megaesôfago chagásico em diferentes períodos

\begin{tabular}{|c|c|c|c|c|}
\hline \multirow[t]{2}{*}{ Períodos } & \multicolumn{2}{|c|}{ Número de Pacientes } & \multirow[t]{2}{*}{ Idade (anos) } & \multirow{2}{*}{$\begin{array}{c}\text { Duração da } \\
\text { disfagia (anos) }\end{array}$} \\
\hline & Total & Média/Ano & & \\
\hline 1955 a 1962 & 147 & 21 & $41(15-84)$ & 10,1 \\
\hline 1988 a 1998 & 100 & 10 & $54(11-83)$ & 4,3 \\
\hline
\end{tabular}

Na Figura 1 está representada a distribuição dos pacientes de acordo com o estádio evolutivo do megaesôfago. No primeiro período predominou o megaesôfago grau III (48\%) e no segundo período o grau II (64\%), sem diferença na porcentagem de megaesôfago graus I e IV.
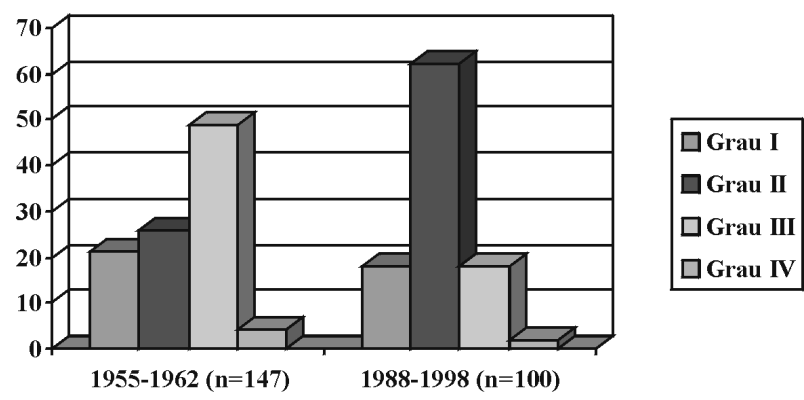

Figura 1 - Distribuição dos pacientes de acordo com o grau do megaesôfago
Quanto ao tratamento cirúrgico, prevaleceram as cirurgias de ressecção no primeiro e a cardiomiotomia no segundo período (Figura 2).
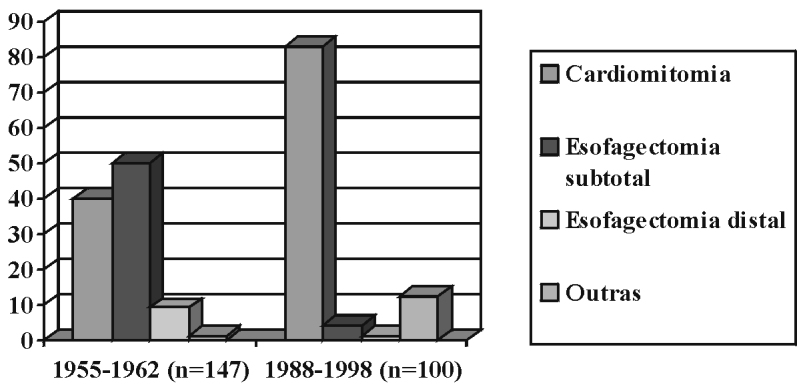

Figura 2 - Cirurgias para megaesôfago chagásico em diferentes períodos de tempo

\section{DISCUSSÃO}

A erradicação do vetor de transmissão da doença de Chagas no Estado de São Paulo foi provavelmente a 
causa fundamental para a redução do número de pacientes portadores de megaesôfago que procuraram o Hospital das Clínicas da FMRP-USP para tratamento no período mais recente, de 1988 a 1998. A possibilidade de transmissão congênita ou por transfusão de sangue é atualmente remota.

Pessoas contaminadas há muitos anos e com a forma indeterminada da doença têm potencial para evoluir para uma forma crônica sintomática e grave ${ }^{4}$. Os pacientes, geralmente acima de 30 a 40 anos, são na grande maioria remanescentes da época em que na região ocorria a transmissão vetorial ou são migrantes originários de regiões onde a doença de Chagas ainda é endêmica.

Apesar dos pacientes das duas séries estudadas se manterem na mesma faixa de variação de idade, a média de idade do segundo grupo foi maior que a do primeiro. Especula-se se a causa está relacionada com a possibilidade de parcela significante dos pacientes ter sido portadora da forma indeterminada, que posteriormente evoluiu para a forma crônica sintomática do megaesôfago.

Embora com média de idade maior que do primeiro grupo, os pacientes do segundo período apresentaram, em média, duração menor da disfagia. Isto traduz a procura de assistência médica mais precoce, que pode se relacionar tanto com a rede assistencial mais ampla e melhor estruturada como com a maior mobilidade e esclarecimento dos pacientes.

Como conseqüência os pacientes do segundo período foram tratados em estádios mais precoces da esofagopatia chagásica, com predomínio do megaesôfago grau II (64\%), enquanto no primeiro grupo predominou o megaesôfago grau III (48\%).

A terapêutica cirúrgica do megaesôfago é sintomática e visa sobretudo suprimir a disfagia de maneira duradoura. A disfagia no megaesôfago chagásico é habitualmente de instalação lenta e gradual e resulta da incoordenação motora do corpo do esôfago (disperistalse) e da dificuldade de abertura da cárdia (acalásia), decorrentes da desnervação dos plexos nervosos intramurais.

No megaesôfago incipiente (grau I) e nos de graus II e III, nos quais a atividade peristáltica está pelo menos parcialmente preservada, a disfagia pode ser suprimida pelo simples tratamento da acalásia, para a qual a cardiomiotomia com fundoplicatura é a melhor opção. No megaesôfago grau III com dólico e no de grau IV (avançado), com ausência ou redução significante da amplitude dos complexos de deglutição, a simples abertura da cárdia não promove o adequado esvaziamento do esôfago e torna-se necessária a sua remoção (esofagectomia subtotal). A esofagectomia distal, com interposição jejunal isoperistáltica à Merendino, é operação de exceção para pacientes com megaesôfago de graus I, II e III, em que operações prévias sobre a cárdia tenham acarretado hérnia hiatal e/ou esofagite de refluxo com estenose péptica do esôfago distal: esta operação tem sido abandonada em decorrência dos resultados insatisfatórios. Outras operações, como as cardioplastias, entre elas a técnica de Serra-Dória, podem ser indicadas para portadores de megaesôfago avançado, nos quais o alto risco cirúrgico contraindica a esofagectomia subtotal, operação mais agressiva e mais sujeita a complicações pós-operatórias.

Assim, os tipos de tratamento cirúrgico correlacionam-se fundamentalmente com o estádio da esofagopatia chagásica, o que explica o predomínio da cardiomiotomia no segundo grupo estudado, em correspondência com a maior prevalência do megaesôfago grau II e o predomínio da esofagectomia subtotal no primeiro grupo, com maior prevalência do megaesôfago avançado.

A esofagectomia subtotal apresenta taxas de morbidez e de mortalidade significativamente maiores do que as da cardiomiotomia ${ }^{6-9}$.

Da análise global pode-se deferir que houve mudança do perfil dos pacientes operados no Hospital das Clínicas da FMRP-USP por megaesôfago chagásico que procuram assistência médica mais precocemente, com tempo de disfagia menor e estádios mais precoces da esofagopatia, permitindo tratamento cirúrgico menos agressivo, com melhores resultados imediatos e tardios.

\section{CONCLUSÃO}

1. O perfil do paciente portador de megaesôfago chagásico atendido no HCFMRP-USP mudou, caracterizando-se sobretudo pela menor duração da disfagia em correspondência com estádio mais precoce da doença.

2. A assistência médica mais precoce resulta em modalidade terapêutica cirúrgica menos agressiva, com perspectiva de melhores resultados.

\section{REFERÊNCIAS}

1. Andreollo NA, Brandalise NA, Lopes R, Leonardi SL. Capítulo 2. In Leonardi SL: Controvérsias na Cirurgia do Aparelho Digestivo. Rio de Janeiro: Medsi; 1991;23-9.

2. Ferreira-Santos R. Tratamento cirúrgico da aperiltalse esofágica (megaesôefago) (Tese Professor Catedrático). Universidade de São Paulo. Faculdade de Medicina de Ribeirão Preto, 1991.

3. Mascarenhas LG, Câmara-Lopes LH, Jurema B, Ferreira-Santos R. Padronização técnica da radiologia do megaesôfago. X Congr Bras Gastroenterol Belo Horizonte, 1958.

4. Andrade SG. Prefácio. In: Malta Jorge. Doença de Chagas. São Paulo, Sarvier, 1996. 
5. Meneghelli UG, Ceneviva R, Guimarães AS. Doença de Chagas e Aparelho Digestivo. In: Ramos O.L, Rothschild H. Atualização terapêutica. $17^{\text {a }}$ ed. São Paulo. Artes Médicas 1995;242-7.

6. Pinotti HW, Pollara WM, Raia AA. Tratamento cirúrgico do megaesôfago avançado pela esofagectomia subtotal sem toracotomia com abertura do diafragma. Rev Ass Med Bras 1980;26:339-43.

7. Cecconello I, Sallum RAA, Rocha JRM, Zilberstein B, Pinotti HW. Indicações e resultados na esofagocardiomiotomia por via aberta na acalásia. IV Curso Internacional de Cirurgia Laparoscópica. Goiânia. In: Cirurgia Videolaparoscópica, 1994;123-4.

8. Pinotti HW. O acesso por transecção mediana do diafragma no tratamento do megaesôfago avançado. Resultados imediatos e tardios. In: Pinotti HS. Acesso ao esôfago torácico por transecção mediana do diafragma. São Paulo: Atheneu;1999; 167-72.

9. Ceconello I, Domene CE, Sallum RAA, Pinotti HW. Esofagectomia transmediastinal no megaesôfago. Rev Col Bras Cir 1988;15:76. 